\title{
Identifying built environmental patterns using cluster analysis and GIS: Relationships with walking, cycling and body mass index in French adults
}

Hélène Charreire ${ }^{1,2}$, Christiane Weber $^{3}$, Basile Chaix ${ }^{4}$, Paul Salze $^{3}$, Romain Casey ${ }^{5}$, Arnaud Banos ${ }^{6}$, Dominique Badariotti ${ }^{3}$, Emmanuelle Kesse-Guyot ${ }^{2}$, Serge Hercberg ${ }^{2}$, Chantal Simon ${ }^{5}$ and Jean-Michel Oppert ${ }^{2,7^{*}}$

\begin{abstract}
Background: Socio-ecological models suggest that both individual and neighborhood characteristics contribute to facilitating health-enhancing behaviors such as physical activity. Few European studies have explored relationships between local built environmental characteristics, recreational walking and cycling and weight status in adults. The aim of this study was to identify built environmental patterns in a French urban context and to assess associations with recreational walking and cycling behaviors as performed by middle-aged adult residents.
\end{abstract}

Methods: We used a two-step procedure based on cluster analysis to identify built environmental patterns in the region surrounding Paris, France, using measures derived from Geographic Information Systems databases on green spaces, proximity facilities (destinations) and cycle paths. Individual data were obtained from participants in the SU. VI.MAX cohort; 1,309 participants residing in the lle-de-France in 2007 were included in this analysis. Associations between built environment patterns, leisure walking/cycling data (h/week) and measured weight status were assessed using multinomial logistic regression with adjustment for individual and neighborhood characteristics.

Results: Based on accessibility to green spaces, proximity facilities and availability of cycle paths, seven built environmental patterns were identified. The geographic distribution of built environmental patterns in the Ile-de-France showed that a pattern characterized by poor spatial accessibility to green spaces and proximity facilities and an absence of cycle paths was found only in neighborhoods in the outer suburbs, whereas patterns characterized by better spatial accessibility to green spaces, proximity facilities and cycle paths were more evenly distributed across the region. Compared to the reference pattern (poor accessibility to green areas and facilities, absence of cycle paths), subjects residing in neighborhoods characterized by high accessibility to green areas and local facilities and by a high density of cycle paths were more likely to walk/cycle, after adjustment for individual and neighborhood sociodemographic characteristics ( $\mathrm{OR}=2.595 \% \mathrm{Cl}$ 1.4-4.6). Body mass index did not differ across patterns.

Conclusions: Built environmental patterns were associated with walking and cycling among French adults. These analyses may be useful in determining urban and public health policies aimed at promoting a healthy lifestyle.

Keywords: Built environment, Urban form, Geographical Information Systems, Cluster analysis, Health-enhancing physical activity, Walking, Cycling, Body Mass Index

\footnotetext{
* Correspondence: jean-michel.oppert@psl.aphp.fr

2UREN, INSERM U557/INRA U1125/CNAM/University of Paris 13/CRNH,

lle-de-France, Bobigny, France

${ }^{7}$ Department of Nutrition, Pitié-Salpêtrière Hospital (AP-HP), University Pierre

et Marie Curie-Paris 6, CRNH Ile-de-France, Paris, France

Full list of author information is available at the end of the article
} 


\section{Background}

According to current socio-ecological models, both individual and neighborhood characteristics contribute to facilitating or limiting health-enhancing behaviors that may help to prevent chronic diseases [1-3]. In addition to social influences, the role of the built environment is being increasingly recognized in urban residential contexts [4-6]. As recently reviewed, environmental built characteristics such as the density of destinations, mixed land use and availability of sidewalks have been found to be associated with physical activity during leisure time and transport in different urban contexts [7]. There is also evidence that characteristics of the built environment related to physical activity are inversely associated with obesity in adults [8]. However, there is a need for additional evidence in each country and between countries.

Walking is the most frequent physical activity, as reported in surveys from North America, Australia and Europe; walking as well as cycling can be performed for both transport and recreation [9-11]. Walking and cycling represent priority targets for public health policies promoting physical activity, as they can be performed throughout the day at low cost. In addition, the promoting of these activities could be beneficial for both health and the environment $[12,13]$. A growing body of literature emphasizes the relationship between built environmental characteristics and walking $[14,15]$. The relationship between the built environment and cycling behavior in adults and, more specifically cycling for recreation and exercise, has been less thoroughly studied $[12,16,17]$.

Proximity to potential destinations is one characteristic of the built environment that appears to be most consistently related to transportation and recreational walking [15]. In addition, the presence of cycle paths is an important environmental feature influencing cycling behavior $[18,19]$. Relationships between green spaces and recreational walking, physical activity and weight status have also been reported [20-23]. Importantly, walking and cycling may be specifically associated with given combinations or patterns of characteristics of the built environment [24]. Using this type of approach, Riva et al. [25] used cluster analysis of data on population density, land use mix and accessibility to proximity services at a census tract level on the island of Montréal; they obtained seven types of active living potential environments.

Cities represent complex systems [26], and urban forms and their overall organization vary widely between Europe, Northern America and Australia [27,28]. This indicates the need for data from different countries and settings [29]. Up until now, European analyses mainly focused on relationships between perceived environmental dimensions and physical activity behavior. Positive associations were reported in Belgium [30] and Portugal [31]. Fewer European studies have investigated the link between objective environmental measurements and physical activity behavior [29]. For example, a Belgian study reported positive associations between high walkabability, walking/cycling for transport and recreational walking [29]. To our knowledge, no European studies have investigated the possible relationship between built environmental patterns and walking/cycling for exercise and recreation.

The first aim of the present study was to identify built environmental patterns in a French urban context using

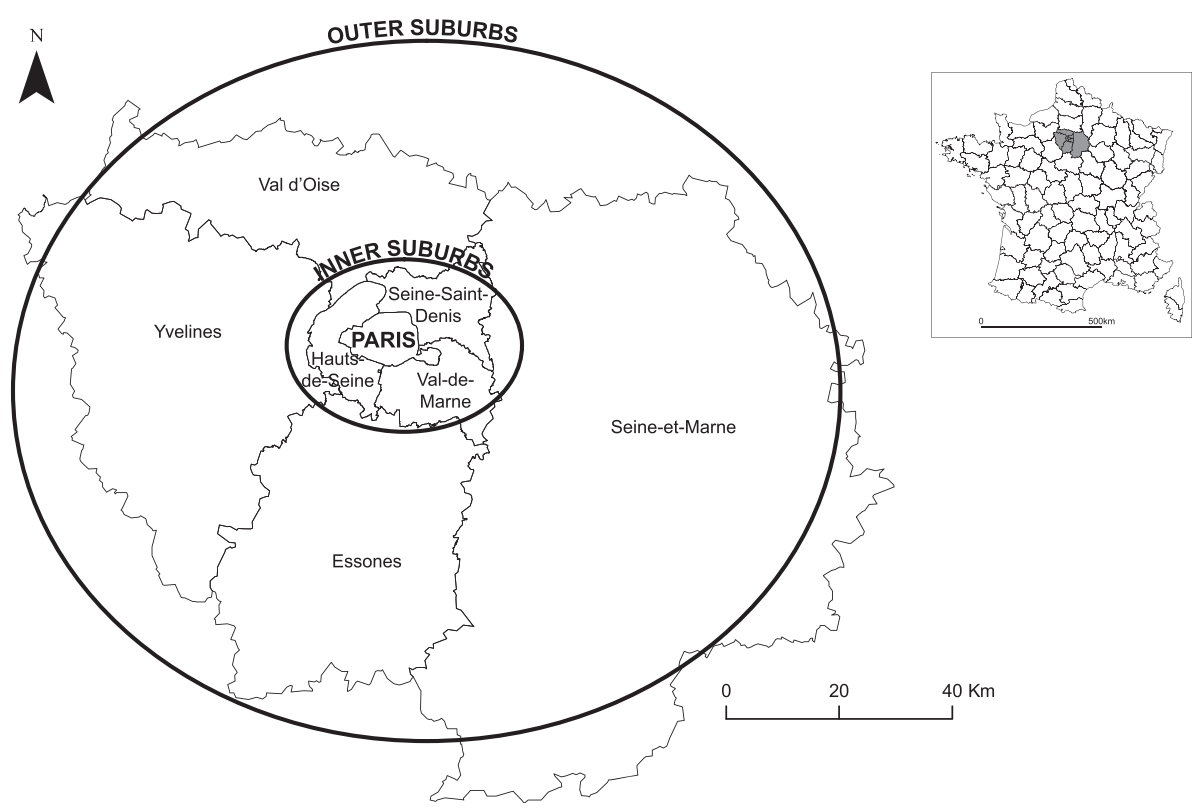

Figure 1 Urban ring model of Paris and seven surrounding departments (Ile-de-France region): Paris, inner suburbs and outer suburbs. 
data on green spaces, cycle paths and proximity facilities in and around Paris. An additional aim was to assess associations between these environmental patterns, body mass index (BMI) and recreational walking and cycling behaviors, as performed by middle-aged adult residents.

\section{Methods \\ Geographic information systems (GIS) environmental characteristics}

The study area included the city of Paris and seven surrounding departments defined administratively as the "Ile-de-France". The overall area covers $12,011 \mathrm{~km}^{2}$ and has more than 11.7 millions inhabitants according to the 2010 French census (see the French National Institute of Statistics and Economic Studies (INSEE) website at www.insee.fr). The Ile-de-France region is traditionally divided into "ring spatial division" comprising three areas: Paris city, inner suburbs and outer suburbs, as represented in Figure 1.

Objective built environment variables were obtained using GIS for all census units IRIS $(n=5,261)$ in the region. French IRIS areas (www.insee.fr) represent neighborhoods on a scale comparable to a census block group in the US. This is the smallest unit for which population census data are available in France. IRIS areas include on average 2,000 inhabitants and are homogeneous in terms of housing and socioeconomic conditions (www.insee.fr).

For each neighborhood, we assessed three geographic variables: spatial accessibility to green spaces (urban parks, public open areas, natural areas and green paths), spatial accessibility to proximity facilities and the availability of cycle paths. Green space data were obtained from databases provided by the Paris Region Urban Planning \& Development Agency (IAU, Ile-de-France) [32]. For each green space, a catchment area (buffer) was calculated according to both size and form of the green space: linear (such as a green path) or surface (such as an urban park), and to geographical limitations (e.g. transport network or river). For green paths, the buffer was $300 \mathrm{~m}$ wide for lines which were $300-1,000$ $\mathrm{m}$ long, $600 \mathrm{~m}$ wide for lines of 1,000-5,000 $\mathrm{m}$ and $1,200 \mathrm{~m}$ wide for those over $5,000 \mathrm{~m}$. For green surfaces, the buffer was $300 \mathrm{~m}$ for green spaces between 1-10 hectares (ha), $600 \mathrm{~m}$ for green spaces between 10-30 ha and, finally, $1,200 \mathrm{~m}$ for those over 30 ha [32]. The variable representing spatial accessibility to green spaces was defined as the percent of green spaces in each neighborhood included in at least one catchment area.

For cycle paths, data were obtained from databases also provided by the Paris Region Urban Planning \& Development Agency (IAU Ile-de-France). We used the length of cycle paths; the variable used in analyses showing the availability of cycle paths was the distance in kilometers for each neighborhood.
Data on geographic distribution of proximity facilities (banks, bakeries, post offices, drugstores and bookstores) were obtained from the INSEE facilities census (www. insee.fr). Spatial accessibility to selected local facilities was estimated by a potential accessibility model $[33,34]$ according to the number of proximity facilities (banks, bakeries, post offices, drugstores and bookstores) in built-up areas within one kilometer Euclidean distance computed from the centroïd (geographical center) [35] of the IRIS administrative unit. Briefly, this spatial accessibility model defined an intensity index of the possible destinations. In the model, these destinations are weighted according to an inverse function of distance. In addition, spatial smoothing was applied to remove artificial barriers defined by administrative borders and to obtain a more realistic estimate of accessibility levels. As previously described [34], the potential accessibility model was implemented in the XLISP-STAT programming environment, and ArcGIS 9.3 (ESRI, Redlands, CA) was used to produce an objective measure of the built environment.

Finally, the spatial accessibility indices for proximity facilities and green catchment areas were categorized into quartiles. The top and bottom quartiles represented high accessibility and low accessibility, respectively. The indicator of availability of cycle paths was also divided into four categories: the first one represented neighborhoods without cycle paths, and the three other categories were defined using tertiles cut-offs.

\section{Built environmental patterns}

A classification procedure based on the successive use of two multivariate statistical methods was used to identify built environmental patterns using GIS objective data. This procedure employed Multiple Correspondence Analysis (MCA) followed by cluster analysis based on hierarchical ascendant classification [36,37].

In a first step, MCA was used to explore interrelationships between multiple dependent variables. This method enables determining the dimensions that provide the most information about relationships between variables [38]. The number of dimensions retained was determined according to the following criteria: eigenvalue $>1$, screen test (plot of the total variance related to each dimension) and interpretability of MCA [36,39]. In our study, groups of spatial accessibility to green areas and proximity facilities and availability of cycle paths defined for each neighborhood were included in the model and treated simultaneously.

In a second step, to identify neighborhood patterns, cluster analysis was performed only with dimensions retained through the MCA procedure (in such a way that a given area belonged to one, and only one, pattern) $[36,40]$. In the present study, patterns provided by cluster 
analysis were based on similarities in GIS environmental variables (i.e. green areas, proximity services, cycle paths). Ward's method was used to define patterns [36,41] and a statistical criterion ("test-value") was used to interpret patterns. As described elsewhere [9,39], we assessed differences between each category of each variable, characterizing the cluster and the relevant category in the overall sample according to a statistical criterion based on a "test-value". In cluster analysis, this test value is interpreted as a criterion that enables classifying categories of the variable by order of importance, thereby facilitating interpretation of results. A positive test value higher than two means that the category of the variable is significantly overrepresented in the cluster compared to the overall sample [9,39]. Note that this procedure allows two categories of the same variable to be overrepresented in the same cluster. MCA and cluster analyses were conducted using SPAD software (Coheris, version 7.3).

\section{Socio-environmental covariables}

The median annual income area data in 2006 from the Tax Income Files (www.insee.fr) was used as an indicator of the environmental socio-economic position. Income data from all neighborhoods were categorized into quartiles. The top and bottom quartiles represented high and low income levels, respectively.

\section{Individual data}

Individual data were obtained from participants in the SU.VI.MAX cohort. The SUpplémentation en VItamines et Minéraux AntioXydants (SU.VI.MAX) study was initially a randomized, double-blind, placebo-controlled, primary prevention trial designed to evaluate the impact of daily antioxidant supplementation at nutritional doses on the incidence of ischemic heart disease and cancer $[42,43]$. A total of 5,056 men aged 45-60 years and 7,679 women aged 35-60 years from throughout France were included between October 1994 and June 1995, with a planned follow-up of 8 years. Details on recruitment, study design and main results of the study have been reported previously [42,43]. All subjects gave informed written consent for the study, which was approved by the Ethical Committee for Studies with Human Subjects at the Paris-Cochin Hospital (CCPPRB $\mathrm{N}^{\mathrm{O}} 706$ ) and the Commission Nationale Informatique et Liberté (CNIL N³34641). In 2007-2009, 6,850 participants in the cohort whose agreement was obtained were enrolled in the SU.VI.MAX 2 study, an observational prospective cohort study designed to investigate the relationship between nutrition and health status in an ageing population [44]. The SU.VI.MAX 2 study was approved by the local ethical committee (CCP $\mathrm{N}^{\circ}$ 2364) and the Commission Nationale de l'Informatique et des Libertés
(CNIL $\mathrm{N}^{\circ}$ 907094). Signed informed consent was obtained from each participant.

\section{Individual level of walking and cycling, weight status and sociodemographic characteristics}

For the present analysis, in order to obtain a similar age range in both sexes, the sample was further restricted to subjects aged 45 or older in 1998. We selected subjects who provided data on leisure time physical activity in 2007 (i.e. the most recent year during which a detailed leisure physical activity questionnaire was sent to the entire cohort) and who resided in the Ile-de-France region in 2007. We also excluded subjects who had been confined to bed for more than 1 month during the period covered by the physical activity questionnaire. Analyses in the present report were thus based on data from 603 men and 706 women.

Data on time spent walking and cycling were obtained using a self-administered French version of the Modifiable Activity Questionnaire (MAQ) [45]. The MAQ has been developed by Kriska et al. to investigate relationships between habitual level of physical activity and diabetes [46]. Criterion validity of the MAQ was assessed against doubly-labelled water [47] and the questionnaire has been described in detail elsewhere [45-47]. Briefly, subjects were asked to report all leisure physical activities performed at least 10 times for $10 \mathrm{~min}$ per session over the past 12 months. Then, detailed information was collected about the type of physical activity (eg. walking, biking) as well as the frequency and duration of each physical activity reported. The assessment of walking and biking was based on the total number of hours per week for each subject. We calculated the total median duration for walking and biking (min/week) among subjects who had reported performing at least one of these activities and we defined three categories for performing walking and cycling: none, less than the median and equal to or above the median value.

Body weight was measured using an electronic scale (Seca, Hamburg, Germany) with the subject wearing indoor clothes and no shoes $[48,49]$. Height was measured under the same conditions to the nearest $0.5 \mathrm{~cm}$ using a wall-mounted stadiometer. Anthropometric data were collected at the inclusion visit in the SU.VI.MAX 2 study (2007-2009). BMI was calculated as body weight divided by height squared $\left(\mathrm{kg} / \mathrm{m}^{2}\right)$.

Individual sociodemographic data were obtained through questionnaires at study entry (sex, age, education level). Age in 2007 was divided into three groups (50-59, 60-69 and $\geq 70$ years). Level of education was coded into three categories according to the highest certification obtained (primary school, high school, university or equivalent). 


\section{Analysis of relationships with individual behaviors}

The associations between built environmental patterns and walking and cycling time were analyzed with multinomial regression models. This analysis was conducted using the category of subjects who did not report walking or cycling as the reference category for the dependent variable. Using covariance analysis, we assessed the associations between built environmental patterns and BMI. Regression and covariance analyses were performed using SAS software (SAS, version 9.3, SAS Institute Inc., Cary, NC, USA). Based on previous literature and on exploratory analyses, adjustment was performed for individual potential confounding factors including age, gender and education level, and for median annual income of neighborhood as an environmental socioeconomic factor.

\section{Results}

\section{Identification and geographic distribution of built} environmental patterns

The first two neighborhood dimensions generated by MCA that accounted for $31.7 \%$ of total initial variance in environmental characteristics were used to conduct cluster analysis. Cluster analysis identified seven distinct neighborhood clusters. Figure 2 illustrates the characteristics of each cluster according to categories of the three built environmental variables (green areas, cycle paths and proximity facilities). Each dot in a given cluster represents a category of a built environmental variable that is significantly overrepresented in the cluster compared to the overall sample.
Mapping of the seven patterns enabled us to highlight the geographic location of each pattern across neighborhoods in the region (Table 1). In Pattern 1, overrepresented categories included high spatial accessibility to local services, high spatial accessibility to green spaces (quartiles 3 and 4) and high availability of cycle paths. Neighborhoods characterized by this pattern $(n=794$, $15.1 \%$ of neighborhoods) were found in the city of Paris, but were also localized at about the same proportions in the suburbs. Pattern 2 was characterized by high spatial accessibility to local services and green spaces, but by low availability of cycle paths. It was also localized both in Paris and the suburbs. Pattern 3 ( $\mathrm{n}=794,15.1 \%)$ was characterized by low spatial accessibility to local services; in contrast, the spatial accessibility to green spaces and availability of cycle paths were high. We mainly observed this pattern in the outer suburbs $(n=494,62.2 \%)$, but also in urban residential areas at the borders of Paris $(\mathrm{n}=103,12.9 \%)$ and in the inner suburbs $(\mathrm{n}=197$, $24.8 \%)$. Pattern $4(\mathrm{n}=755,14.4 \%)$ reflected neighborhoods characterized by high spatial accessibility to local services, by the absence of cycle paths, and it was localized in the suburban areas (more in the inner than in the outer suburbs). Pattern $5(n=629,12.0 \%)$ reflected a group of neighborhoods characterized by high access to green spaces and proximity facilities and by an absence of cycle paths. Pattern 5 was mainly found in Paris and the inner suburbs. Pattern $6(n=663,12.6 \%)$ was characterized by an absence of cycle paths and by medium spatial accessibility to proximity facilities and green spaces, and was localized in both types of suburbs. Pattern $7(n=833,15.8 \%)$ was mainly localized at the

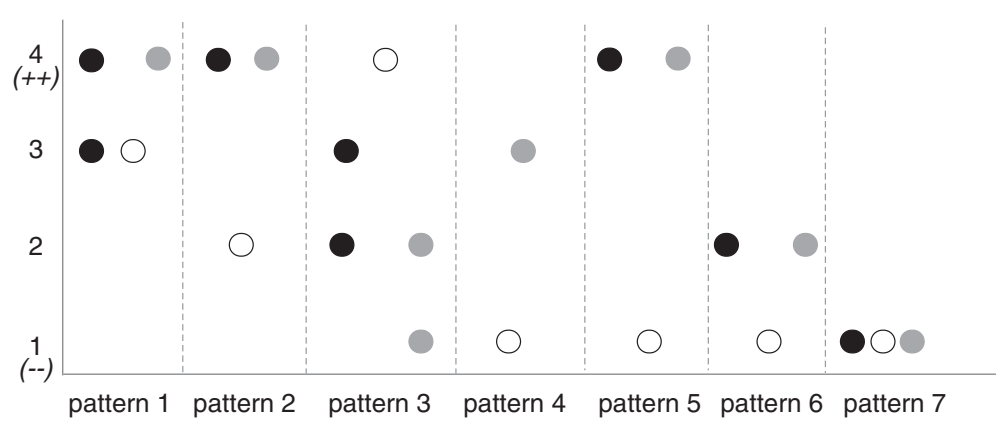

Spatial accessibility to green spaces

Availability of cycle paths

Spatial accessibility to proximity facilities

Figure 2 Characteristics of the seven built environmental patterns according to categories of spatial accessibility to green spaces, proximity facilities and availability of cycle paths. On the $y$ axis are represented the 4 categories used for each variable. For green spaces and proximity facilities, the top and bottom quartiles represented high (++) and low accessibility (--). For cycle paths, (--) represented neighborhoods without cycle paths and the three other categories were defined using tertiles. Dots indicate those categories overrepresented in each cluster compared to the overall sample. For example, for Pattern 1, both quartiles 3 and 4 for spatial accessibility to green spaces were overrepresented. 
Table 1 Geographic distribution of built environmental patterns in the Ile-de-France region

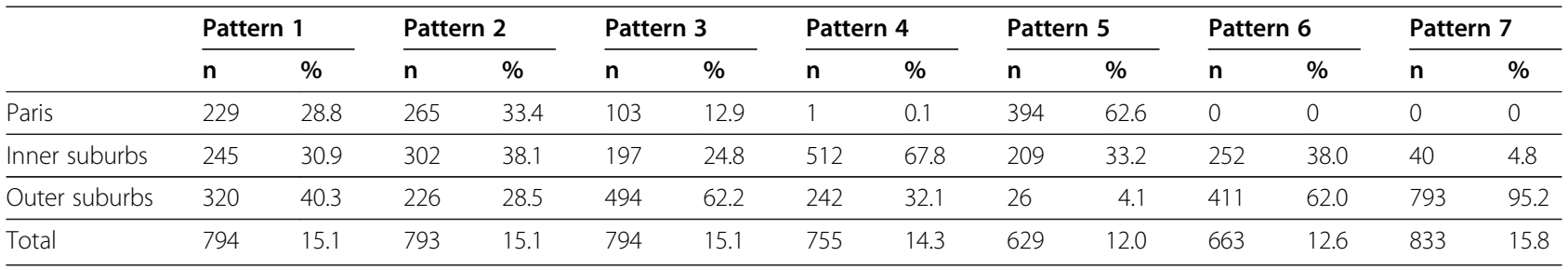

borders of the outer suburbs in neighborhoods characterized by low spatial accessibility to green spaces and proximity facilities and by an absence of cycle paths.

\section{Individual characteristics}

Characteristics of subjects, including sociodemographic characteristics, walking and cycling behaviors and BMI, are shown in Table 2. Mean \pm s.d. age was over 60 in both genders. About two-thirds of men and half of the women were retired in 2007. For both genders, more than $60 \%$ of subjects performed recreational walking. In walking and cycling duration categories, $25.9 \%$ of subjects (339) did no walking or cycling.

\section{Relationships with built environmental patterns}

In multinomial regression models, pattern 7 was used as the reference pattern. Associations between built environmental patterns and walking and cycling categories are shown in Figure 3. After adjustment for individual characteristics (age and education level) and median neighborhood income, the likelihood of walking and cycling over the median weekly duration was increased in pattern 1 compared with the reference pattern (pattern 7) $(\mathrm{OR}=2.595 \% \mathrm{CI}$ 1.4-4.6). The likelihood of walking and cycling also increased for both patterns $3(\mathrm{OR}=2.2$ CI95\% 1.3-3.9) and 5 (OR $=2.5$ CI95\% 1.4-4.9) compared with the reference pattern. There were no significant associations between built environmental patterns and the category of subject who had reported walking and cycling less frequently than the median weekly duration. There was no significant difference in BMI across patterns (data not shown).

\section{Discussion}

The first aim of this study was to identify built environmental patterns in a European urban context. To

Table 2 Characteristics of study subjects

\begin{tabular}{|c|c|c|c|c|}
\hline & \multicolumn{2}{|c|}{ Men $(n=603)$} & \multicolumn{2}{|c|}{ Women $(n=706)$} \\
\hline & $\mathbf{N}$ & $\%$ & $\mathbf{N}$ & $\%$ \\
\hline \multicolumn{5}{|l|}{ Age } \\
\hline Age (year) ${ }^{1}$ & $64.9 \pm 4.6$ & & $62.9 \pm 5.3$ & \\
\hline $50-59$ years & 82 & 13.6 & 198 & 28.1 \\
\hline 60-69 years & 389 & 64.5 & 408 & 57.8 \\
\hline$\geq 70$ years & 132 & 21.9 & 100 & 14.2 \\
\hline \multicolumn{5}{|l|}{ Education level } \\
\hline Primary school & 132 & 21.8 & 125 & 17.7 \\
\hline High school & 193 & 32.0 & 263 & 37.3 \\
\hline University or equivalent & 267 & 44.4 & 296 & 41.9 \\
\hline Missing value & 11 & 1.8 & 22 & 3.1 \\
\hline \multicolumn{5}{|l|}{ Working status } \\
\hline Not retired & 153 & 25.4 & 271 & 38.4 \\
\hline Retired & 415 & 68.8 & 361 & 51.1 \\
\hline Missing value & 35 & 5.8 & 74 & 10.5 \\
\hline \multicolumn{5}{|l|}{ Physical activity performed } \\
\hline Walking & 425 & 70.5 & 453 & 64.2 \\
\hline Cycling & 178 & 29.5 & 102 & 14.4 \\
\hline No walking or cycling & 0 & 0.0 & 151 & 21.4 \\
\hline Median total duration h/week (Q1-Q3) Aligment with Walking/Cycling & $1.15(0-3.5)$ & & $1.1(0.1-3.1)$ & \\
\hline Body mass index $\left(\mathrm{kg} / \mathrm{m}^{2}\right)^{1}$ & $26.3 \pm 3.4$ & & $24.6 \pm 4.3$ & \\
\hline
\end{tabular}

${ }^{1}$ Mean \pm standard deviation. 


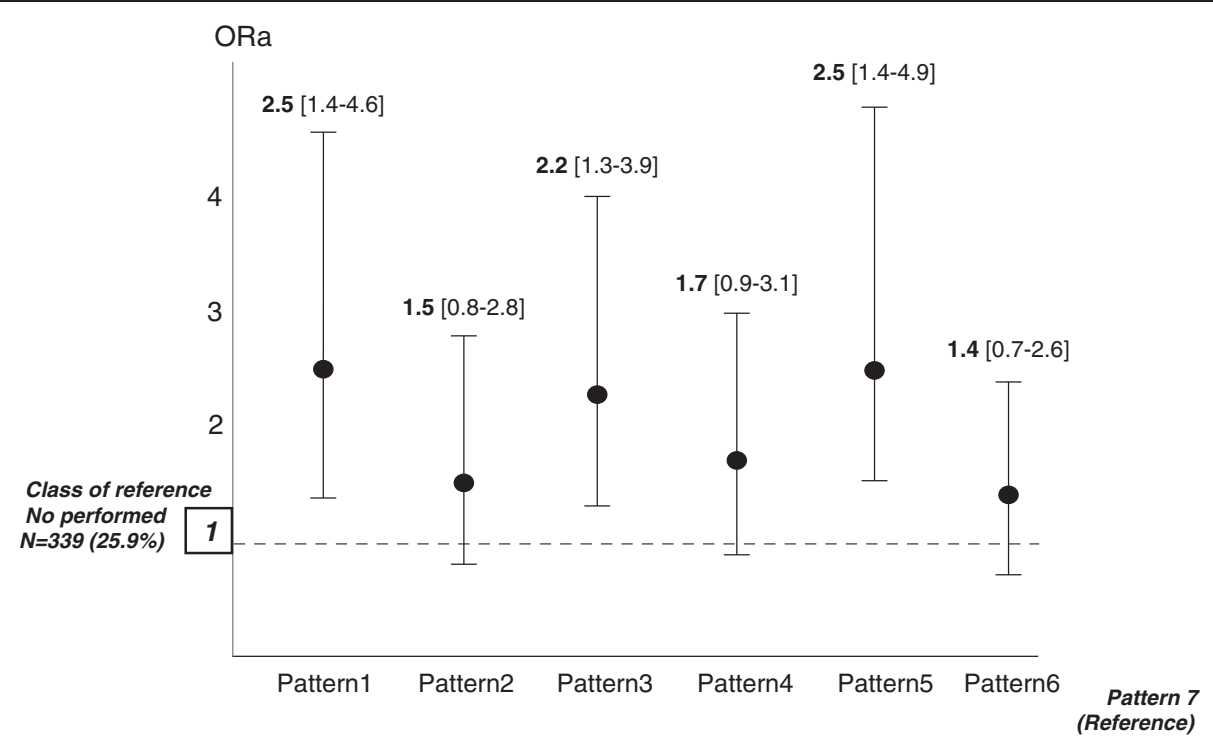

Figure 3 Adjusted $^{\mathrm{a}}$ odds ratios (ORa) for the likelihood of walking and cycling over weekly duration categories $(n=487,37.2 \%)$ by built environmental patterns $\mathbf{b}^{\mathbf{b}} .{ }^{\mathrm{a}}$ Adjusted for individual characteristics (age, education level) and socio-economic environmental characteristics (median income) ${ }^{\text {b }}$ Built environment patterns (1 to 7 ) are those described on Figure 2.

approach the complexity of urban forms in European settings, we used a methodology enabling us to analyze the co-occurrence of several important characteristics of the built environment. Using GIS datasets of urban characteristics and a combination of MCA and cluster analysis, we identified seven built environmental patterns in the region around Paris, France. A pattern characterized by low spatial accessibility to green spaces and proximity facilities and an absence of cycle path was found only in neighborhoods in the outer suburbs, whereas patterns characterized by higher spatial accessibility to green spaces and proximity facilities and the presence of cycle paths were more evenly distributed across the region. In addition, we found an increased likelihood of walking and cycling in subjects residing in neighborhoods characterized by high accessibility to green spaces and proximity facilities compared to those living in neighborhoods with low spatial accessibility to green spaces and proximity facilities and without cycle paths, after adjusting for individual sociodemographic characteristics (age, gender and education level) and median neighborhood income.

One strength of the present study lies in our analysis of built environmental patterns that take into account specificities of the physical environment in urban contexts. Examination of spatial distribution of the seven patterns and analyses of the relation between these patterns and walking and cycling behaviors reveal the complexity of the urban built environment in this study region (Ile-deFrance), beyond a simple division between the city center, the inner and the outer suburbs. In the current investigation, we were specifically interested in pedestrian and cycling-related built environments based on three variables: green spaces, cycle paths and proximity to facilities. Previous research suggested the importance of built environment attributes facilitating walking, such as high residential density, street connectivity and land use mix [24,50-52]. In the present study, information on residential density was not included in the analyses of environmental patterns because of strong correlations observed between population density (using built-up area density) and spatial accessibility to proximity services (Spearman rank correlation $=0.73 \mathrm{p}<0.0001$ ). In addition, information on the presence of sidewalks on both sides of the street (a component of walkability) was not found relevant to the situation in France. We estimated the availability of sidewalks (length of sidewalks in kilometers in each neighborhood in Paris) and the density of road network (excluding large roads and highways) in each neighborhood of the study region; however, the variability of these characteristics was not significant (data not shown). In French suburbs, there are almost always sidewalks alongside the streets, and these may include cycle paths. Indeed, our patterns with high availability of cycle paths were localized both within Paris and in the suburbs (inner and outer).

To categorize neighborhoods into homogeneous patterns according to built environmental characteristics, we used a combination of MCA and hierarchical cluster analysis. This approach has been used in previous studies to define social and demographic neighborhood patterns and to assess individual health outcomes according to these social patterns [53]. As described by Escofié et al. [36], MCA was used as a preliminary step for 
classification due to its role as a filter for eliminating non-relevant dimensions that might be assimilated with 'statistical noise'. In a second step, most significant factorial dimensions obtained by MCA were included in cluster analysis to generate groups of neighborhoods with similar built environmental characteristics. Integration of these two methods enables analyses based on the most significant interrelations between categories of built environmental variables [54] and might better explain the diversity and natural grouping of characteristics, thereby overcoming limitations due to use of either factor or cluster analysis [53].

An important feature of our study was that we were able to assess the relationships between built environmental patterns and walking and cycling behaviors in a sample of middle-aged adult residents. We found that patterns 1, 3 and 5 were significantly associated with the likelihood of walking and cycling over the median weekly duration. In order to generate hypotheses concerning these relationships with built environmental patterns, we assessed the geographic distribution of the seven neighborhood patterns. The principal difference between patterns 1 and 3, both localized across the three zones of the region, was in the availability of cycle paths, lower in pattern 3 than in the reference pattern. There is evidence that the presence of cycle paths is important in creating an active living local environment. In New Orleans, an increase in the average number of riders (both adults and children) per day was observed after the first on-street bike lane was painted on the streets of the city in 2007 [18]. However, in our study, increased likelihood of walking and cycling was also found for pattern 5, characterized by an absence of cycle paths. Depending on the urban context, this relationship may be due to other aspects of the built environment that may influence walking and cycling, such as specific equipment in the green spaces $[21,55,56]$ or the amount of traffic [57].

In contrast to positive relationships with walking and cycling of some built environment patterns, no significant association was found with BMI. This is consistent with findings from a recent systematic review [5] which suggested that some built environmental features were associated with an increased level of physical activity, especially walking, but not with BMI. In addition, in another recent review [20] the relationship between green space and weight was found inconsistent. As emphasized by the UK Foresight Report [58], excess weight and obesity represent highly complex systems shaped by multiple interdependent factors acting throughout the lifespan. Therefore, to be able to demonstrate a direct and simple relationship between built environment patterning and weight status would be unexpected. Especially, the cross-sectional design of available studies cannot take into account potential time-lags between exposure to built environment and body weight change [20], pointing to the importance of longitudinal studies.

In the present study, walking and cycling data were available only for recreational physical activity. It should be noted, however, that more than $50 \%$ of study subjects (68.6\% in men and $51.1 \%$ in women) were retired. Therefore, information on commuting activities may not be relevant. In a recent systematic review focusing on older adults (over 65 years), Van Cauwenberg et al. [59]. pointed out that, while non-significant associations between walkability indices and recreational walking were found in the US and Australia a significant positive association was found in Belgium. In a European urban context, Van Dyck et al. assessed the link between walking and cycling (transport and recreation) and the level of walkability in an urban city (Ghent) in Belgium [29]. That study showed that a high level of walkability was positively associated with a high level of walking both during transport and recreation.

\section{Limitations}

Several limitations of our study need to be pointed out. The design was cross-sectional and thus we could not establish causal relationships between built environmental patterns and walking and cycling behaviors. Nor can we rule out a bias related to residential neighborhood self-selection. Neighborhood selection may be determined by numerous factors based on financial constraints, availability of equipment, transportation infrastructures and lifestyle $[60,61]$. In our study, subjects were volunteers in a nutritional intervention study $[42,43]$. Although characteristics of the participants of the SU.VI.MAX study were found to be close to those of the national population according to socioeconomic status and to the distribution of major risk factors for cardiovascular disease and cancers [42,43], these subjects may have had healthier lifestyles.

Another limitation was that measurements of walking and cycling were derived from self-report and, as noted in previous studies $[62,63]$, this may be a source of potential misclassification. In general, it is known that physical activity (especially information concerning duration and frequency) tends to be overreported and sedentary behavior is underestimated [62]. In addition, although our patterns were based on analyses of objective GIS built environmental data, we lacked information on environmental variables which may promote or limit walking and cycling behaviors, such as road traffic and safety [64], and specific characteristics of green spaces such as access points and the presence of equipment $[21,55,56]$. Another limitation is related to geographic scale and area arrangement. Results are likely to vary with the size and the arrangement of areas, with larger 
administrative units being more heterogeneous, which may occur when the same range of data, calculated at various spatial levels, produces different results $[65,66]$. To limit a potential bias related to the relationship between size and location, the variable used for measuring spatial accessibility to facilities was defined according to the built-up area of each IRIS.

Finally, our study territory was limited to one European city (Paris and suburbs); further studies are needed to determine whether they can be generalized to other European urban settings.

\section{Conclusions}

Based on accessibility to green spaces and proximity facilities and the availability of cycle paths, we identified specific local built environmental patterns in a French region. Using individual physical activity data, we were able to show that subjects living in neighborhoods characterized by high accessibility to green spaces and proximity facilities and high availability of cycle paths did significantly more walking and cycling than those living in neighborhoods with low accessibility and availability. No significant relationship was found for overall corpulence, as assessed by the BMI. These findings emphasize the complexity of urban forms at regional and local levels, and suggest the need to provide culture-specific approaches to characterizing neighborhood contexts in relation to healthy behaviors. Physical inactivity is recognized as a major risk factor for ill health and the onset of non-communicable diseases [67]. In this context, our analyses may be useful for influencing urban and public health policies aimed at promoting healthy lifestyles in urban settings.

\section{Abbreviations}

GIS: Geographical Information Systems; BMI: Body Mass Index; INSEE: French National Institute of Statistics and Economic Studies; IRIS: "Ilôts Regroupés pour I'Information Statistique"; IAU: Paris Region Urban Planning \& Development Agency; MCA: Multiple Correspondence Analysis; MAQ: Modifiable Activity Questionnaire.

\section{Competing interests}

The authors declare that they have no competing interests.

\section{Authors' contributions}

$\mathrm{HC}$ designed the study, performed statistical analyses, interpreted results and drafted the manuscript. CW, BC, PS, RC, AB, DB, EKG, SH and CS participated in interpreting results, editing the manuscript and critically revising it. JMO supervised the design, analysis and interpretation of data, as well as writing of the manuscript. SH is a coordinator of the SU.VI.MAX study. All authors read and approved the final manuscript.

\section{Acknowledgements}

This work is part of the ELIANE (Environmental LInks to physical Activity, Nutrition and hEalth) study. ELIANE is a project supported by the French National Research Agency (Agence Nationale de la Recherche, ANR-07-PNRA004, coordinator JM Oppert). Part of the work was also funded by the Compalimage Project (ANR-05-PNRA 010; coordinator, S Hercberg). We thank the staff of the SU.VI.M.AX study and also the volunteers who participated in the study. We thank the Paris Region Urban Planning \& Development Agency (IAU, lle-de-France).

\section{Author details}

'Lab-Urba, Urbanism Institute of Paris, University of Paris Est, Créteil, France. ${ }^{2}$ UREN, INSERM U557/INRA U1125/CNAM/University of Paris 13/CRNH, Ile-de-France, Bobigny, France. ${ }^{3}$ Image, Ville, Environnement, CNRS ERL730, University of Strasbourg, Strasbourg, France. ${ }^{4}$ INSERM U707, University Pierre et Marie Curie-Paris 6, UMR-S 707, Paris, France. ${ }^{5} \mathrm{CarMeN}$, INSERM U1060/ INRA U1235/University of Lyon, CRNH Rhône-Alpes, Lyon, France. ${ }^{6}$ Géographie-Cité, UMR 8504 CNRS, Paris, France. ${ }^{7}$ Department of Nutrition, Pitié-Salpêtrière Hospital (AP-HP), University Pierre et Marie Curie-Paris 6, CRNH Ile-de-France, Paris, France.

Received: 5 September 2011 Accepted: 1 May 2012

Published: 23 May 2012

\section{References}

1. Richard L, Gauvin L, Raine K: Ecological Models Revisited: Their Uses and Evolution in Health Promotion Over Two Decades. Annu Rev Public Health 2011, 32:307-326.

2. Sallis JF, Cervero RB, Ascher W, Henderson KA, Kraft MK, Kerr J: An ecological approach to creating active living communities. Annu Rev Public Health 2006, 27:297-322.

3. Giles-Corti B, Donovan RJ: The relative influence of individual, social and physical environment determinants of physical activity. Soc Sci Med 2002, 54:1793-1812

4. Brownson RC, Hoehner CM, Day K, Forsyth A, Sallis JF: Measuring the built environment for physical activity: state of the science. Am J Prev Med 2009, 36:599-123 e112.

5. Durand CP, Andalib M, Dunton GF, Wolch J, Pentz MA: A systematic review of built environment factors related to physical activity and obesity risk: implications for smart growth urban planning. Obes Rev 2011, 12:73-182.

6. Ball K, Timperio AF, Crawford DA: Understanding environmental influences on nutrition and physical activity behaviors: where should we look and what should we count? Int I Behav Nutr Phys Act 2006, 3:33.

7. Bergeron P, Reyburn S: L'impact de l'environnement bâti sur l'activité physique, l'alimentation et le poids: Institut national de santé publique du Québec; 2010. Eds.

8. Lake A, Townsend T, Alvanides S: Obesogenic environments: complexities, perceptions and objective measures. Oxford: Wiley-Blackwell; 2010.

9. Charreire H, Casey R, Salze P, Kesse-Guyot E, Simon C, Chaix B, Banos A, Badariotti D, Touvier M, Weber C, Oppert JM: Leisure-time physical activity and sedentary behavior clusters and their associations with overweight in middle-aged French adults. Int J Obes (Lond) 2010, 34:1293-1301.

10. Armstrong T, Bauman A, Davies J: Physical activity patterns of Australian adults. Results of the 1999 National Physical Activity Survey. In In Book Physical activity patterns of Australian adults. Results of the 1999 National Physical Activity Survey. City: Canberra: Australian Institute of Health and Welfare; 2000. Editor ed.^eds.).

11. DHHS: Physical activity and health: a report of the Surgeon General. In Book Physical activity and health: a report of the Surgeon General. City:; 1996. Editor eds.

12. Ogilvie D, Bull F, Powell J, Cooper AR, Brand C, Mutrie N, Preston J, Rutter H: An applied ecological framework for evaluating infrastructure to promote walking and cycling: the iConnect study. Am J Public Health 2011, 101:473-481

13. Lindsay G, Macmillan A, Woodward A: Moving urban trips from cars to bicycles: impact on health and emissions. Aust N Z J Public Health 2011, 35:54-60.

14. Owen N, Humpel N, Leslie E, Bauman A, Sallis JF: Understanding environmental influences on walking; Review and research agenda. Am J Prev Med 2004, 27:67-76.

15. Saelens B, Handy S: Built environment correlates of walking: a review. Med Sci Sports Exerc 2008, 40:S550-S566.

16. Wendel-Vos GC, van Hooijdonk C, Uitenbroek D, Agyemang C, Lindeman EM, Droomers M: Environmental attributes related to walking and bicycling at the individual and contextual level. J Epidemiol Community Health 2008, 62:689-694.

17. Owen N, De Bourdeaudhuij I, Sugiyama T, Leslie E, Cerin E, Van Van Dyck D, Bauman A: Bicycle use for transport in an Australian and a Belgian city: associations with built-environment attributes. J Urban Health 2010, 87:189-198. 
18. Parker K, Gustat J, Rice J: Installation of bicycle lanes and increased ridership in an urban, mixed-income setting in New-Orleans, Louisiana. J Phys Act Health 2011, 8:S98-S102.

19. Pucher J, Dill J, Handy S: Infrastructure, programs, and policies to increase bicycling: an international review. Prev Med 2010, 50(Suppl 1):S106-S125.

20. Lachowycz K, Jones AP: Greenspace and obesity: a systematic review of the evidence. Obes Rev 2011, 12:e183-e189.

21. Giles-Corti B, Broomhall MH, Knuiman M, Collins C, Douglas K, Ng K, Lange A, Donovan RJ: Increasing walking: how important is distance to, attractiveness, and size of public open space? Am J Prev Med 2005, 28:169-176.

22. Coombes $\mathrm{E}$, Jones AP, Hillsdon M: The relationship of physical activity and overweight to objectively measured green space accessibility and use. Soc Sci Med 2010, 70:816-822.

23. McCormack GR, Rock M, Toohey AM, Hignell D: Characteristics of urban parks associated with park use and physical activity: a review of qualitative research. Health Place 2010, 16:712-726.

24. Saelens BE, Sallis JF, Black JB, Chen D: Neighborhood-based differences in physical activity: an environment scale evaluation. Am J Public Health 2003, 93:1552-1558.

25. Riva M, Apparicio P, Gauvin L, Brodeur JM: Establishing the soundness of administrative spatial units for operationalising the active living potential of residential environments: an exemplar for designing optimal zones. Int J Heal Geogr 2008, 7:43.

26. Batty M: The Size, Scale, and Shape of Cities. Science 2008, 319:769-771.

27. Arbury J: From urban sprawl to compact city: an analysis of urban growth management in Auckland: MA Thesis. University of Auckland, Geography and Environmental Science; 2005

28. Bertaud A: Metropolis: A Measure of the Spatial Organization of 7 Large Cities. 2001. http://alain-bertaud.com.

29. Van Dyck D, Cardon G, Deforche B, Sallis JF, Owen N, De Bourdeaudhuij I: Neighborhood SES and walkability are related to physical activity behavior in Belgian adults. Prev Med 2010, 50(Suppl 1):S74-S79.

30. De Bourdeaudhuij I, Sallis J, Saelens B: Environmental correlates of physical activity in a sample of Belgian adults. Am J Health Promot 2003, 18:83-92.

31. Santos R, Silva P, Santos P, Ribeiro JC, Mota J: Physical activity and perceived environmental attributes in a sample of Portuguese adults: results from the Azorean Physical Activity and Health study. Prev Med 2008, 47:83-88.

32. Legenne C: La desserte en espace vert: un outil de suivi de la trame verte d'agglomération. 2009. http://www.iaurif.org.

33. Hansen W: How accessibility shapes land use. Journal of the American Institute of Planners 1959, 25:73-76.

34. Salze P, Banos A, Oppert J, Charreire H, Casey R, Simon C, Chaix B, Badariotti $D$, Weber $C$ : Estimating spatial accessibility to facilities on the regional scale: an extended commuting-based interaction potential model. Journal: International Journal of Health Geographics 2011, 10:2.

35. Thornton LE, Pearce JR, Kavanagh AM: Using Geographic Information Systems (GIS) to assess the role of the built environment in influencing obesity: a glossary. Int J Behav Nutr Phys Act 2011, 8:71

36. Escofié B, Pagés J: Analyses factorielles simples et multiples 3e ed. Paris: Dunod; 1998.

37. Everitt B: Cluster analysis. London: Heineman Educational Books; 1980.

38. Greenacre M: Theory and Applications of Correspondence Analysis. London: Academic; 1984

39. Lebart L, Piron M, Morineau A: Statistique exploratoire multidimensionnelle. Visualisation et inférence en fouilles de données. 4e edth edition. Paris.; 2006.

40. Michels KB, Schulze MB: Can dietary patterns help us detect diet-disease associations? Nutr Res Rev 2005, 18:241-248.

41. Pryer JA, Nichols R, Elliott P, Thakrar B, Brunner E, Marmot M: Dietary patterns among a national random sample of British adults. J Epidemiol Community Health 2001, 55:29-37.

42. Hercberg S, Preziosi P, Briancon S, Galan P, Triol I, Malvy D, Roussel AM, Favier A: A primary prevention trial using nutritional doses of antioxidant vitamins and minerals in cardiovascular diseases and cancers in a general population: the SU.VI.MAX study-design, methods, and participant characteristics. SUpplementation en VItamines et Mineraux AntioXydants. Control Clin Trials 1998, 19:336-351.

43. Hercberg S, Galan P, Preziosi P, Bertrais S, Mennen L, Malvy D, Roussel AM, Favier A, Briancon S: The SU.VI.MAX Study: a randomized, placebo- controlled trial of the health effects of antioxidant vitamins and minerals. Arch Intern Med 2004, 164:2335-2342.

44. Kesse-Guyot E, Peneau S, Ferry M, Jeandel C, Hercberg S, Galan P: Thirteen-year prospective study between fish consumption, long-chain n-3 fatty acids intakes and cognitive function. J Nutr Health Aging 2011, 15:115-120.

45. Vuillemin A, Oppert JM, Guillemin F, Essermeant L, Fontvieille AM, Galan P, Kriska AM, Hercberg S: Self-administered questionnaire compared with interview to assess past-year physical activity. Med Sci Sports Exerc 2000, 32:1119-1124.

46. Kriska AM, Knowler WC, LaPorte RE, Drash AL, Wing RR, Blair SN, Bennett PH, Kuller LH: Development of questionnaire to examine relationship of physical activity and diabetes in Pima Indians. Diabetes Care 1990, 13:401-411.

47. Pereira MA, FitzerGerald SJ, Gregg EW, Joswiak ML, Ryan WJ, Suminski RR, Utter AC, Zmuda JM: A collection of Physical Activity Questionnaires for health-related research. Med Sci Sports Exerc 1997, 29:S1-S205.

48. Czernichow S, Bertrais S, Oppert JM, Galan P, Blacher J, Ducimetiere P, Hercberg S, Zureik M: Body composition and fat repartition in relation to structure and function of large arteries in middle-aged adults (the SU.VI. MAX study). Int J Obes (Lond) 2005, 29:826-832.

49. Bertrais S, Beyeme-Ondoua JP, Czernichow S, Galan P, Hercberg S, Oppert $J M$ : Sedentary behaviors, physical activity, and metabolic syndrome in middle-aged French subjects. Obes Res 2005, 13:936-944.

50. Cerin E, Saelens BE, Sallis JF, Frank LD: Neighborhood Environment Walkability Scale: validity and development of a short form. Med SCi Sports Exerc 2006, 38:1682-1691.

51. Robertson-Wilson J, Giles-Corti B: Walkability, neighborhood design and obesity. In Obesogenic environments: complexities, perceptions and objective measures. Edited by Lake A, Townshend TG, Alvanides S. Oxford (UK): WileyBlackwell Publishing; 2010.

52. Leslie E, Coffee N, Frank L, Owen N, Bauman A, Hugo G: Walkability of local communities: using geographic information systems to objectively assess relevant environmental attributes. Health Place 2007, 13:111-122.

53. Li Y-S, Chuang Y-C: Neighborhood effects on an individual' health using neighborhood measurements developed by factor analysis and cluster analysis. J Urban Health 2008, 86(1):5-18.

54. Berg H, Gregersen N, Laflamme L: Typical patterns in road-traffic accidents during driver training. An explorative Swedish national study. Accident Analysis \& Prevention 2004, 36:603-608.

55. Kaczynski AT, Potwarka LR, Saelens BE: Association of park size, distance, and features with physical activity in neighborhood parks. Am J Public Health 2008, 98:1451-1456.

56. Maroko A, Maantay J, Sohler N, Grady K, Arno P: The complexities of measuring access to parks and physical activity sites in New York City: a quantitative and qualitative approach. Int J Health Geogr 2009, 8:34.

57. Foster CE, Panter JR, Wareham NJ: Assessing the impact of road traffic on cycling for leisure and cycling to work. Int J Behav Nutr Phys Act 2011, 8:61.

58. Butland B, Jebb S, Kopelman P, McPherson K, Thomas S, Mardell J, Parry V: Foresight. Tackling obesities: future choices. Project report. 2007. http://www. bis.gov.uk/foresight.

59. Van Cauwenberg J, De Bourdeaudhuij I, De Meester F, Van Dyck D, Salmon J, Clarys P, Deforche B: Relationship between the physical environment and physical activity in older adults: a systematic review Health Place 2011, 17(1):458-69.

60. Boone-Heinonen J, Gordon-Larsen P, Guilkey DK, Jacobs DR Jr, Popkin BM: Environment and Physical Activity Dynamics: The Role of Residential Self-selection. Psychol Sport Exerc 2011, 12:54-60

61. McCormack GR, Shiell A: In search of causality: a systematic review of the relationship between the built environment and physical activity among adults. Int J Behav Nutr Phys Act 2011, 8:125.

62. Shephard RJ: Limits to the measurement of habitual physical activity by questionnaires. Br J Sports Med 2003, 37:197-206. discussion 206.

63. Sallis JF, Saelens BE: Assessment of physical activity by self-report: status, limitations, and future directions. Res Q Exerc Sport 2000, 71:S1-S14.

64. Wendel-Vos W, Droomers M, Kremers S, Brug J, van Lenthe F: Potential environmental determinants of physical activity in adults: a systematic review. Obes Rev 2007, 8:425-440. 
65. Macintyre S, Macdonald L, Ellaway A: Do poorer people have poorer access to local resources and facilities? The distribution of local resources by area deprivation in Glasgow, Scotland. Soc Sci Med 2008, 67:900-914.

66. Openshaw S: The modifiable areal unit problem. Norwich, UK: Geo Books; 1984

67. Beaglehole R, Bonita R, Horton R, Adams C, Alleyne G, Asaria P, Baugh V, Bekedam H, Billo N, Casswell S, et al: Priority actions for the noncommunicable disease crisis. Lancet 2011, 377:1438-1447.

doi:10.1186/1479-5868-9-59

Cite this article as: Charreire et al: Identifying built environmental patterns using cluster analysis and GIS: Relationships with walking, cycling and body mass index in French adults. International Journal of Behavioral Nutrition and Physical Activity 2012 9:59.

\section{Submit your next manuscript to BioMed Central and take full advantage of:}

- Convenient online submission

- Thorough peer review

- No space constraints or color figure charges

- Immediate publication on acceptance

- Inclusion in PubMed, CAS, Scopus and Google Scholar

- Research which is freely available for redistribution 